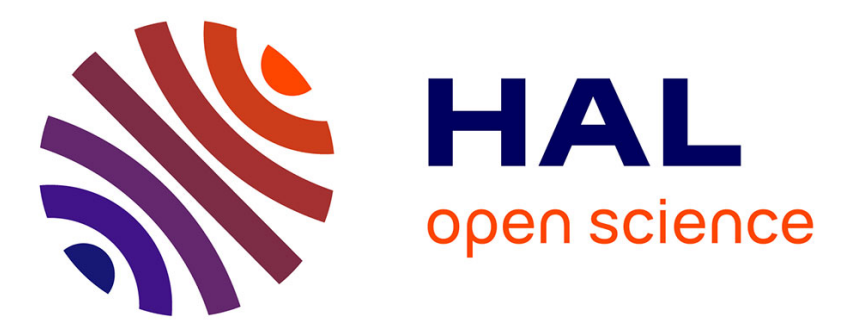

\title{
Air-broadened N2O line-shape parameters and their temperature dependences by requantized classical molecular dynamics simulations
}

\author{
N.H. Ngo, H.T. Nguyen, M.T. Le, H. Tran
}

\section{- To cite this version:}

N.H. Ngo, H.T. Nguyen, M.T. Le, H. Tran. Air-broadened N2O line-shape parameters and their temperature dependences by requantized classical molecular dynamics simulations. Journal of Quantitative Spectroscopy and Radiative Transfer, 2021, 267, pp.107607. 10.1016/j.jqsrt.2021.107607 . hal-03388949

\author{
HAL Id: hal-03388949 \\ https://hal.science/hal-03388949
}

Submitted on 28 Oct 2021

HAL is a multi-disciplinary open access archive for the deposit and dissemination of scientific research documents, whether they are published or not. The documents may come from teaching and research institutions in France or abroad, or from public or private research centers.
L'archive ouverte pluridisciplinaire HAL, est destinée au dépôt et à la diffusion de documents scientifiques de niveau recherche, publiés ou non, émanant des établissements d'enseignement et de recherche français ou étrangers, des laboratoires publics ou privés. 


\title{
Air-broadened $\mathrm{N}_{2} \mathrm{O}$ line-shape parameters and their temperature dependences by requantized classical molecular dynamics simulations
}

\author{
N. H. Ngo ${ }^{1, *}$, H. T. Nguyen ${ }^{1,2,3}$, M.T. Le ${ }^{1}$, H. Tran ${ }^{2, \dagger}$ \\ ${ }^{1}$ Faculty of Physics, Hanoi National University of Education, 136 Xuan Thuy, Cau Giay, \\ Hanoi, Viet Nam \\ ${ }^{2}$ Laboratoire de Météorologie Dynamique, IPSL, CNRS, Sorbonne Université, École \\ normale supérieure, PSL Research University, Ecole polytechnique, F-75005 Paris, France \\ ${ }^{3}$ REMOSAT, University of Science and Technology of Hanoi (USTH), Vietnam Academy \\ of Science and Technology (VAST)
}

\begin{abstract}
In this paper, we used requantized Classical Molecular Dynamics Simulations (rCMDS), corrected by the room temperature air-broadening coefficients measured in the $v_{3}$ band of $\mathrm{N}_{2} \mathrm{O}$, to predict line-shape parameters including the broadening coefficient, its speed dependence component, the Dicke narrowing and the line-mixing coefficients, associated with various lineshape models for air-broadened $\mathrm{N}_{2} \mathrm{O}$ absorption lines. For that, we first computed the autocorrelation functions of the $\mathrm{N}_{2} \mathrm{O}$ dipole moment, responsible for the absorption transitions. The Fourier-Laplace transform of these functions directly yields the absorption spectra. Calculations were made for three temperatures 200, 250 and $296 \mathrm{~K}$ and 1 atm of $\mathrm{N}_{2} \mathrm{O}$ /air mixtures and for a large range of values of the ratio between the Doppler and Lorentzian widths. The obtained spectra were then fitted with the quadratic speed-dependent Voigt profile including the first-order line mixing using a multi-spectrum fitting procedure. Comparisons with values determined from room temperature high-precision measurements in the $v_{3}$ band of $\mathrm{N}_{2} \mathrm{O}$ by using the same profile [Loos et al, J. Quant. Spectrosc. Rad. Transf., 151, 2015, 300-309] show that our retrieved line broadening coefficients are overestimated by about $4 \%$. The difference between the measured and predicted line broadening coefficients was used to empirically correct the rCMDS auto-correlation functions and thus the corresponding absorption spectra. These latter were then fitted with the Voigt, the speed-dependent Voigt, and the speed-dependent Nelkin-Ghatak profiles, all of them being associated with the first-order line-mixing approximation, providing the corresponding lineshape parameters for lines up to $J^{\prime \prime} \leq 60$. The temperature dependences of various line-shape
\end{abstract}

\footnotetext{
* Corresponding author: hoa.nn@hnue.edu.vn

${ }^{\dagger}$ Corresponding author: htran@1md.jussieu.fr
} 
parameters were also deduced. The results show a very good agreement with available experimental data for all the considered parameters.

\section{Introduction}

Nitrous oxide $\left(\mathrm{N}_{2} \mathrm{O}\right)$ is a long-lived atmospheric trace gas with a lifetime of about 150 years, playing an important role in radiative transfer and atmospheric chemistry [1-3]. $\mathrm{N}_{2} \mathrm{O}$ is estimated to contribute for about $6 \%$ to the global warming effect and it is predicted to be the most important ozone-depleting emission in the twenty-first century $[1,3,4]$. The concentration of $\mathrm{N}_{2} \mathrm{O}$ in the Earth's atmosphere has been (and still is) monitored by both ground-based and spaceborne instruments (e.g. [5-7]). Precise spectroscopic parameters of $\mathrm{N}_{2} \mathrm{O}$ lines for wide ranges of pressure and temperature are needed to accurately retrieve atmospheric $\mathrm{N}_{2} \mathrm{O}$ concentrations. Parameters characterizing refined effects on the line shape, beyond the usual collision-induced line broadening and shifting coefficients of the Voigt profile, were shown to have an important role for highaccuracy retrieval (e.g. [8,9]). For $\mathrm{N}_{2} \mathrm{O}$, most of the previous laboratory spectroscopic studies used the Voigt profile to model the line shapes. The most studied non-Voigt effect for $\mathrm{N}_{2} \mathrm{O}$ is collisional line mixing in the $\mathrm{Q}$ branch of some perpendicular bands (e.g. [10-13]). In [14], line-mixing and speed-dependence effects were taken into account in the analysis of air-broadened $\mathrm{N}_{2} \mathrm{O}$ spectra in the $v_{3}$ band, measured at room temperature with a Fourier Transform Spectrometer. This band was then measured and analyzed in [15] with the same line-shape model, the obtained line parameters being in good agreement with those of [14]. In [16] spectroscopic parameters for twenty $\mathrm{N}_{2}$ broadened $\mathrm{N}_{2} \mathrm{O}$ lines in the $3 v_{3}$ band were retrieved from spectra measured with a comb-assisted cavity ring-down spectrometer using the speed-dependent Voigt profile. More recently, Odintsova et al [17] used several line-shape models including the speed-dependent Voigt and speeddependent Nelkin-Ghatak, to analyze eight self-broadened $\mathrm{N}_{2} \mathrm{O}$ lines in the $3 v_{1}+2 v_{2}$ band. Further efforts are needed to provide complete sets of $\mathrm{N}_{2} \mathrm{O}$ line-shape parameters and their temperature dependences for applications and populating spectroscopic databases.

While line-shape parameters are usually obtained from fits of laboratory measured spectra, they can also be predicted by theoretical calculations. Quantum scattering calculations were performed in order to compute the line shapes and predict line-shape parameters for $\mathrm{H}_{2}, \mathrm{HD}$ perturbed by $\mathrm{He}[18,19]$ and $\mathrm{CO}$ in Ar [20]. Because of their high computational cost, such calculations were mainly applied to simple systems. Thanks to the increasing computer power and 
in conjunction with the availability of more accurate full-dimensional potential energy surfaces, this method will be probably applied to more complex molecular systems in the future. On the other hand, line-shape parameters for various molecular systems such as $\mathrm{CO}_{2}$ perturbed by $\mathrm{N}_{2}$ and $\mathrm{O}_{2}$ [21,22], $\mathrm{CO}$ in various perturbers [23], $\mathrm{O}_{2}$ in air [24] were successfully predicted using requantized classical molecular dynamic simulations (rCMDS). The principle of these calculations is very simple: based on the classical time evolution of a system containing a large number of molecules, one can compute the time dependent auto-correlation function of the dipole moment, responsible for the transition. The Fourier-Laplace transform of the latter directly yields the corresponding absorption spectrum. Using an adapted requantization procedure, one can deduce the absorption spectrum with the corresponding rotational structure. The simulated spectrum can then be fit with phenomenological line-shape models yielding the corresponding line-shape parameters. This method was recently successfully used to predict line-shape parameters for $\mathrm{N}_{2}$ [21] and $\mathrm{O}_{2}$-broadened [22] $\mathrm{CO}_{2}$ lines, for instance.

In this work, rCMDS are used to obtain line-shape parameters and their temperature dependence for air-broadened $\mathrm{N}_{2} \mathrm{O}$ lines. The intermolecular potential used and the computational method are described in Sec. 2. Since the rCMDS-predicted line broadening coefficients can differ from measured values by several percent, a correction procedure, as proposed for $\mathrm{CO}$ in [23], was applied, using a few experimental information from [14]. This correction procedure is presented in Sec. 3. The resulting rCMDS spectra were then analyzed using the usual Voigt, the speeddependent Voigt as well as the speed-dependent Nelkin-Ghatak profiles, all including the first order line-mixing. This analysis procedure is described in Sec. 3 and the obtained line-shape parameters are presented and compared with existing experimental and theoretical data in Sec. 4 . Conclusions and perspectives are given in Sec.5.

\section{Calculations procedure and potential energy surface used}

Classical molecular dynamics simulations (CMDS) were performed at $1 \mathrm{~atm}$ and three temperatures 200,250 and $296 \mathrm{~K}$ for $\mathrm{N}_{2} \mathrm{O}$-air mixtures with $50 \%$ of air, which contains $80 \%$ of $\mathrm{N}_{2}$ and $20 \%$ of $\mathrm{O}_{2}$. The principle of these calculations can be found in [25] and some of our previous papers [21,26]. Here, only interactions between $\mathrm{N}_{2} \mathrm{O}$ and $\mathrm{N}_{2}, \mathrm{~N}_{2} \mathrm{O}$ and $\mathrm{O}_{2}$ were authorized in the calculations. This is equivalent to simulating a system in which $\mathrm{N}_{2} \mathrm{O}$ molecules are infinitely diluted in $0.5 \mathrm{~atm}$ of air. The molecules are considered as rigid rotors. A site-site functional form 
with Coulombic and atom-atom contributions was used to represent the interaction potentials between $\mathrm{N}_{2} \mathrm{O}$ and $\mathrm{N}_{2}$, and between $\mathrm{N}_{2} \mathrm{O}$ and $\mathrm{O}_{2}$ molecules. The molecular geometries, the charges and sites were taken from [27] for $\mathrm{N}_{2} \mathrm{O}$ and from [28] for $\mathrm{N}_{2}$ and $\mathrm{O}_{2}$ molecules. The atom-atom contributions were calculated as 12-6 Lennard-Jones potentials whose parameters were determined using the Lorentz-Berthelot combination rules [29] from parameters for $\mathrm{N}_{2} \mathrm{O}-\mathrm{N}_{2} \mathrm{O}$ [27], $\mathrm{N}_{2}-\mathrm{N}_{2}$ and $\mathrm{O}_{2}-\mathrm{O}_{2}[28]$ interactions.

For each considered temperature, simulations were made for $3.10^{8}$ active molecules, which were distributed in thirty thousand boxes with periodic boundary conditions; each of them contains $2.10^{4}$ molecules. The size of each box is determined using the perfect gas law, from the number of molecules and the considered temperature and pressure. At the initial time, the center-of mass (c.o.m) position of each molecule was randomly chosen with the constraint that molecules should be separated from each other by distances of at least $9 \AA$, ensuring that no situation involving pairs of unphysically strongly interacting molecules is generated. This condition imposes the use of a temporization time which was $20 \mathrm{ps}$ in the calculations. Translational and angular speeds verifying the Maxwell-Boltzmann distribution were initialized while random oriented c.o.m. velocity vector and molecular axis were attributed. The parameters (c.o.m. position, velocity, angular momentum, and molecular orientation) describing the classical state of each molecule were then computed for each time step up to about 1000 ps.

A requantization procedure, proposed in [26] for $\mathrm{CO}_{2}$, was used here to requantify the classical rotation of the $\mathrm{N}_{2} \mathrm{O}$ molecules. Specifically, for a molecule of rotational angular speed $\omega$, we find the corresponding integer $J$ for which $\hbar J / I$ (where $I$ is the moment of inertia) is the closest to $\omega$. This corresponds to matching the classical rotational frequency with the quantum position of the $\mathrm{P}$ branch lines. Once $J$ is found, $\omega$ is requantized by changing it to $\omega=\hbar J / I$ while the angular orientation is kept unchanged. The auto-correlation function of the dipole moment, assumed along the molecular axis (as it is the case for the asymmetric and symmetric stretching absorption bands of $\mathrm{N}_{2} \mathrm{O}$ ) was then calculated during the requantized CMDS (rCMDS). The Doppler effect associated to the translational motion was taken into account in this auto-correlation function using Eq. (2) of [26].

For each considered temperature, eight values of the Doppler width $\Gamma_{D}$ were used in the calculations, providing a broad range of values of the ratio $\Gamma_{L} / \Gamma_{D}$ (from about 0.07 to 7 ), $\Gamma_{L}$ being the Lorentz width. This enables to cover a wide range of situations, from the near purely Doppler 
to collision-dominant regimes. Since all the effects of vibrational motion were disregarded in our rCMDS, from the point of view of collisional effects on the line shape, this corresponds to calculations for eight values of pressure with a unique Doppler width. The area-normalized absorption coefficient was obtained as the Fourier-Laplace transform of the auto-correlation function of the dipole moment. The spectra were thus calculated without the use of any adjustable parameter. Note that they do not show any pressure shift since our rCMDS do not take into account the dephasing of the dipole, which is associated with the fact that the effects of intermolecular interactions for molecules in the upper and lower states of the optical transitions are different.

\section{Correcting the rCMDS and analysis procedure}

As shown in $[21,22,24]$, line-shape parameters predicted by rCMDS can be of several percent different from accurate measured values. Refined line-shape parameters such as the speed dependence of the broadening and the Dicke narrowing coefficient have a small impact on the line profile so that differences of several percent are completely negligible contrary to the linebroadening coefficients for which these differences can lead to large change on the calculated line shape. A correction is thus necessary. In a previous work [23], we demonstrated that the entire line-shape parameters set for a line can be obtained by correcting the rCMDS results using a value of the line-broadening coefficient measured at a single given pressure. Specifically, for each line, the difference between the rCMDS-predicted and the measured line broadenings is used to correct the auto-correlation functions calculated by rCMDS [23].

In this work, the measured values of [14] are retained for this correction procedure. In [14], air-broadened line-shape parameters for lines with $J^{\prime \prime} \leq 40\left(J^{\prime \prime}\right.$ being the rotational quantum number of the lower level) in the $v_{3}$ band of $\mathrm{N}_{2} \mathrm{O}$ were retrieved from FTS spectra measured at room temperature for a wide range of pressure (from 100 to 1000 mbar). The speed-dependent Voigt (sdV) profile including the first-order line mixing (LM) was used to fit the measured line shapes. To correct the rCMDS, we first fit the rCMDS-calculated spectra with the same line-shape model using a multi-spectrum fitting procedure. In the fits, the Doppler widths were fixed to values used in the simulations. For each line, the area and a linear base line were adjusted individually for each Doppler width while the other parameters were constrained to be the same for all spectra. The pressure-shift and its speed dependence were fixed to zero since no pressure shift effect is predicted by our rCMDS. Figure 1 shows a comparison between the line broadening coefficients, 
$\gamma_{0}$, predicted by rCMDS (in black) and the measured values of [14]. As can be observed, rCMDSpredicted values are larger from 2 to $6 \%$ when compared to the experimental coefficients. Note that values for lines with $J^{\prime \prime}$ up to 60 were predicted by rCMDS while measurements were limited to $J^{\prime \prime} \leq 40$. The measured values were thus extrapolated for $J^{\prime \prime}$ up to 60 using a Padé approximant, the corresponding values being also shown in Fig. 1. Measured values for $J^{\prime \prime} \leq 40$ and extrapolated values for $40<J^{\prime \prime} \leq 60$ were then used to correct the rCMDS results. Similarly to what was done in [23], for each transition, we multiply the computed dipole auto-correlation functions by $\exp (-2 \pi c P \Delta \gamma t)$ in which $\Delta \gamma=\gamma_{0}^{\text {meas }}-\gamma_{0}^{r C M D S}, c$ being the speed of light in vacuum and $P$ the pressure of the calculation. The Fourier-Laplace transform of these corrected auto-correlations functions is again computed providing the corrected rCMDS-calculated spectra for the considered transition. Note that the correction procedure is applied to the calculations performed at room temperature only, the temperature dependences of the line-shape parameters being deduced from non-corrected rCMDS spectra.

The three line-shape models: Voigt (V), speed-dependent Voigt (sdV) [30] and speeddependent Nelkin-Ghatak (sdNG) profiles [31,32] were retained to analyze the corrected rCMDScalculated spectra. The quadratic speed dependence model $[33,34]$ is used to represent the speed dependence of the line broadening in the sdV and sdNG profiles. In all cases, line-mixing effects were also taken into account through the use of the first-order approximation [35]. Our results show that the sdNG and sdV profiles lead to very similar fit residuals, both in much better agreement with the simulated spectra than the Voigt profile (see Fig. 2 for instance).

The temperature dependences of the different line-shape parameters were obtained directly from fits of rCMDS spectra without any corrections. They were modeled using the usual power law, i.e. $A(T)=A\left(T_{0}\right)\left(\frac{T_{0}}{T}\right)^{n_{A}}$ with $T_{0}=296 \mathrm{~K}, A(T)$ being either the line broadening coefficient, the speed dependence component, the Dicke narrowing or the line-mixing parameter. From the values of $A(T)$ obtained from fits of the (non-corrected) rCMDS-calculated spectra at 200, 250 and $296 \mathrm{~K}$, the temperature exponents $n_{A}$ were obtained for each line. All the obtained parameters and their temperature dependences are listed in Table 1, and presented in the next section. The uncertainties of the rCMDS-deduced values are not reported here since it is almost impossible to accurately determine them. Indeed, this would require the determination of those due to the used 
intermolecular potential, to the numerical approaches used in the rCMDS, and to the retrieval of the parameters searched for in the fits.
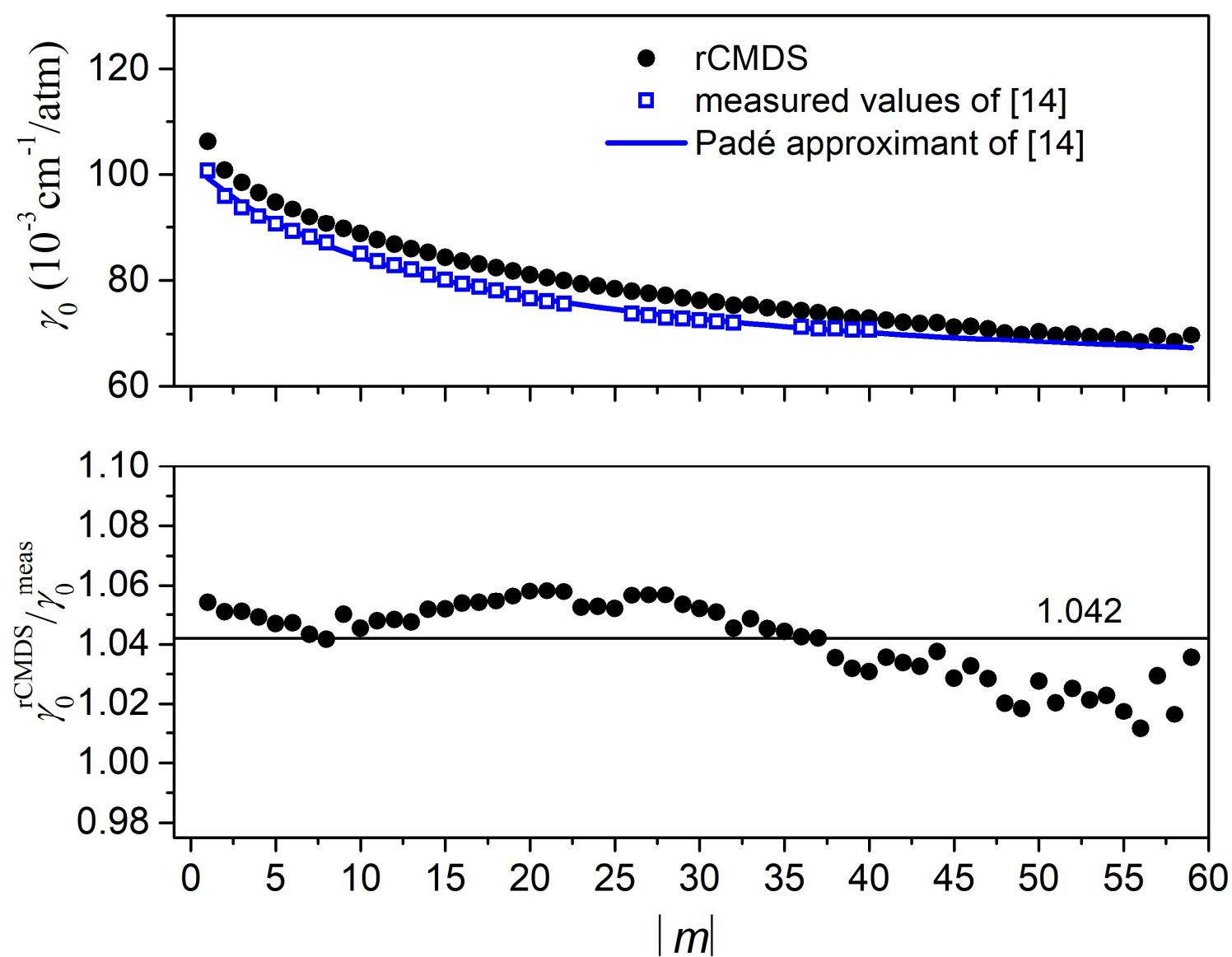

Fig.1: Top: Comparison between line broadening coefficients deduced from fits of rCMDScalculated spectra with the sdV and first-order LM model (black circles) and values of [14] (blue squares) obtained from fits of FTS measured spectra with the same line-shape model. Bottom: the ratio of the rCMDS-predicted broadening coefficients and measured values. $m$ is the rotational quantum number in the lower level of the lines, $m=-J^{\prime \prime}$ in the P branch. 


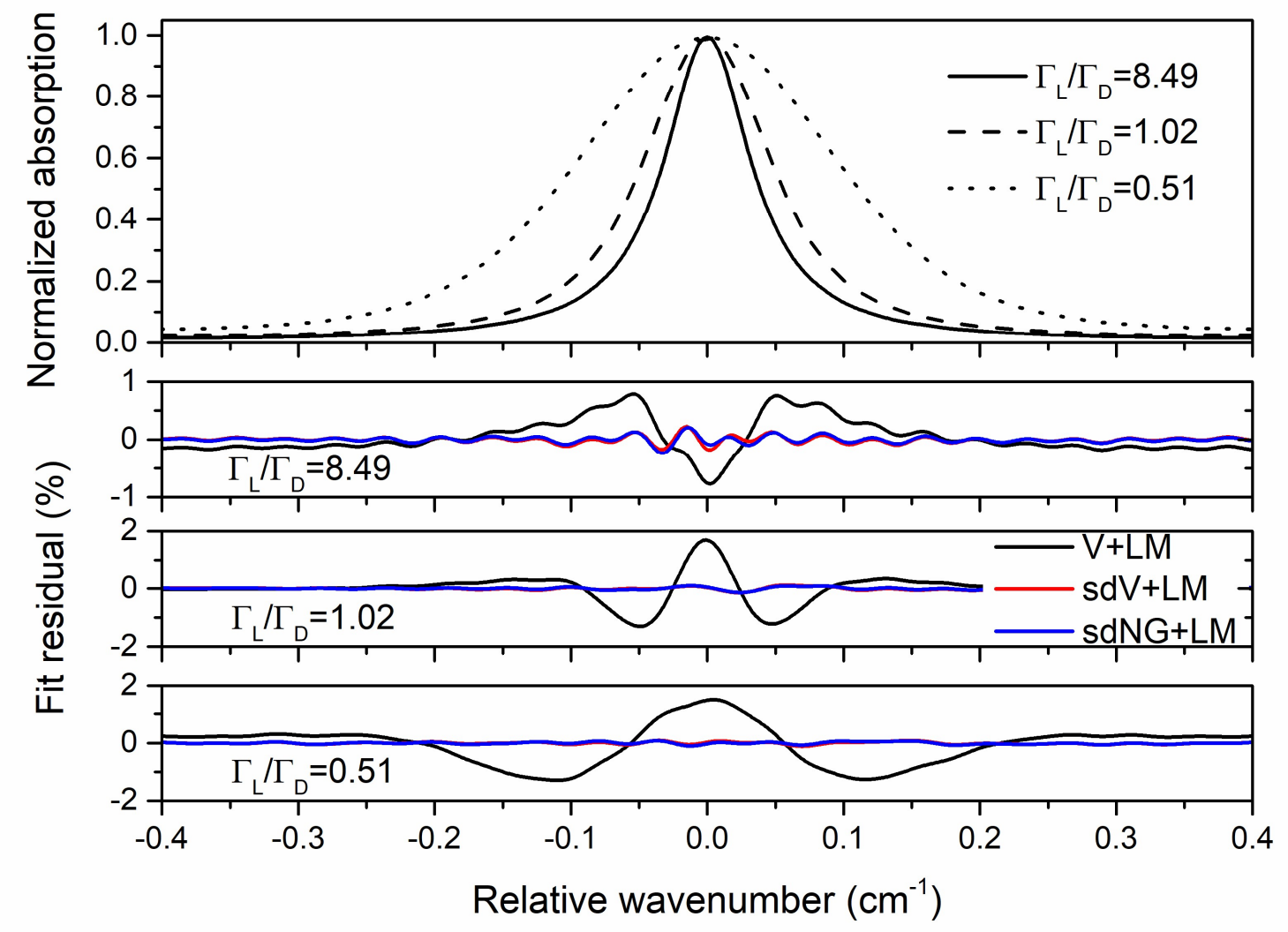

Fig. 2: (Top panel) Example of spectra calculated from the corrected rCMDS auto-correlation functions for the $P(18)$ line of $\mathrm{N}_{2} \mathrm{O}$ broadened by air at $T=296 \mathrm{~K}$ and $P_{\text {air }}=0.5$ atm and for three values of the Doppler width $\Gamma_{D}=0.0046,0.0382$ and $0.0764 \mathrm{~cm}^{-1}$ leading to three values of $\Gamma_{L} / \Gamma_{D}=8.49$, 1.02 and 0.51 , respectively. (Bottom) The corresponding residuals obtained from multi-fitting these calculated spectra using the $V$, sdV and sdNG profiles, LM effect was also taken into account.

\section{Line-shapes parameters and their temperature dependences}

\subsection{Air-broadening coefficients}

The room temperature air-broadening coefficients, $\gamma_{0}$, obtained from multi-fitting the rCMDS spectra, calculated and corrected as described previously, with the $\mathrm{V}, \mathrm{sdV}$, sdNG profiles together with the first-order line mixing, are plotted in Fig. 3. Because of the limited signal-tonoise ratio of the calculated spectra (from 500 to 3000, depending on the line and on the Doppler width used), we could not determine reliable line-shape parameters for lines with $|m|$ greater than 60. Comparisons between the coefficients obtained with the three profiles show that the values obtained with the $\mathrm{V}$ profile are, on average, $4 \%$ smaller than those obtained with the sdV and sdNG models. To the best of our knowledge, the speed-dependence of the line width for air-broadened 
$\mathrm{N}_{2} \mathrm{O}$ lines was investigated in [14] and [15] only, both for the $v_{3}$ band. Since our rCMDS are corrected using the experimental values of [14], our rCMDS-deduced values for $\gamma_{0}$ using the sdV profile are almost identical to those of [14] (see Table 1 of the present paper and Table 3 of [14]). Note that the latter were retained in the last version of the HITRAN database [36]. The results of [15] are plotted in Fig. 3, showing a very good agreement with an average difference of about 1\% between our sdV values and those of [15].

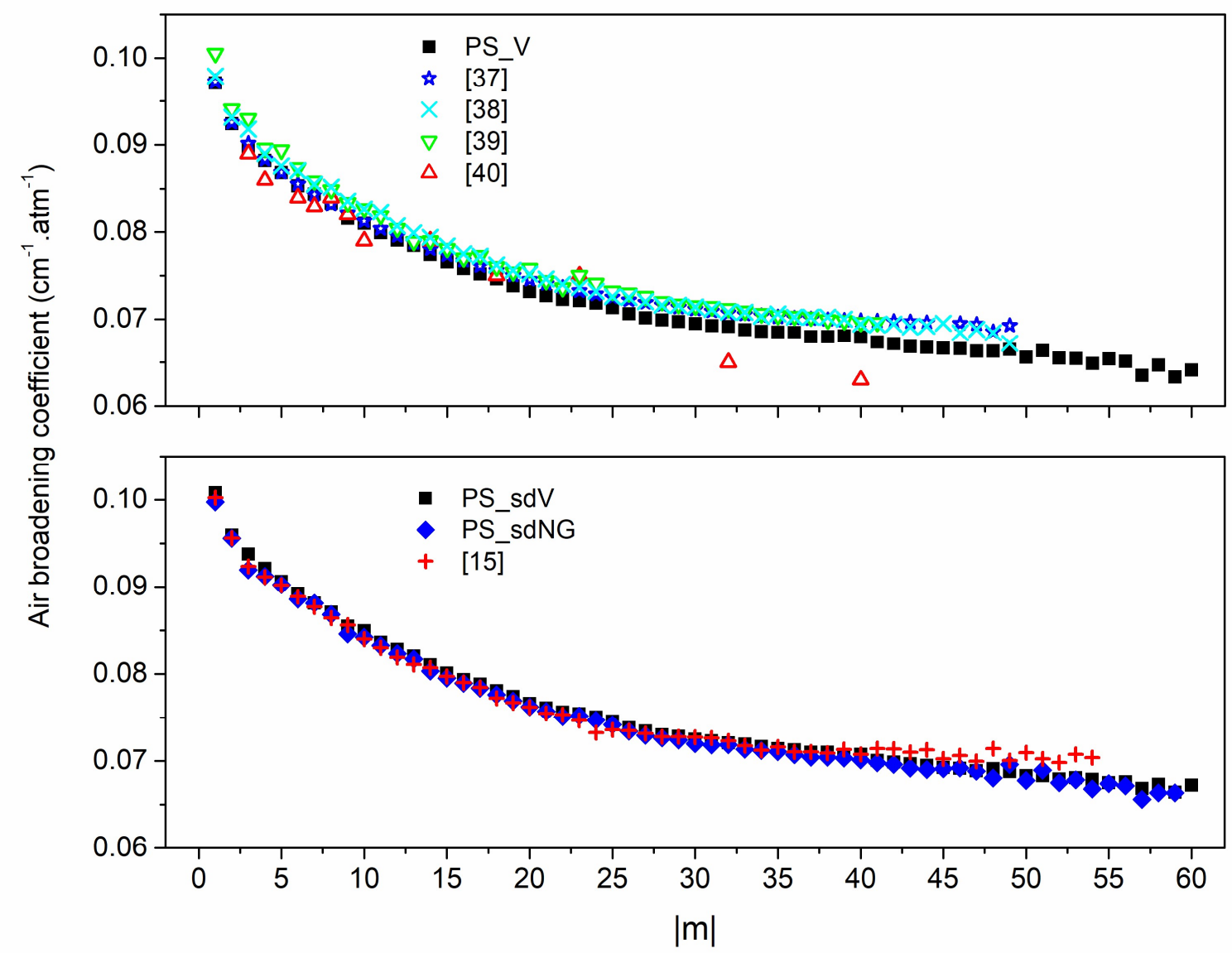

Fig.3: Room temperature air-broadening coefficients retrieved from the corrected-rCMDS calculations (PS-present study) with the Voigt profile (upper panel) and with the sdV and sdNG profiles (lower panel) versus $|\mathrm{m}|$. Measured values from [37-40] obtained with the Voigt profile and those of [15] with the sdV model are also plotted for comparison.

Our Voigt values are compared with those of [37-39] (Fig. 3), obtained from fits of measured spectra in the $v_{3}$ band using the same profile. Since the vibrational dependence of the line broadening for $\mathrm{N}_{2} \mathrm{O}$ is likely negligible, the measured data of [40], obtained with the Voigt profile for the $3 v_{3}$ band are also plotted in Fig. 3 for comparison. For $|m|<40$, a very good 
agreement is observed for all the considered datasets with a standard deviation smaller than $2 \%$, except for that of [40]. The differences are slightly larger for $|m|>40$. As mentioned in [37], [38] and [39], the uncertainties of the measured values were estimated to be about $4 \%, 2 \%$ and $3 \%$, respectively, numbers which are of the same order as their differences with our rCMDS-deduced values. For instance, the average difference between our values and those of [38] is $2 \%$ only.

The obtained temperature exponents for $\gamma_{0}$ are shown in Fig. 4 together with the experimental values of [37,39] and the constant value (i.e. 0.75) adopted in HITRAN2016 [36]. As can be observed, the calculated values obtained with the three considered line shapes are very close to each other. For small values of $|m|$, the predicted results are in good agreement with those of [39]. Both show a rather linear rotational dependence of $n_{\gamma_{0}}$ while it is a sinusoidal variation in [37]. At high $|m|$, the predicted values of $n_{\gamma_{0}}$ are smaller than the experimental ones by about 0.1 (which is, as estimated in [39], the uncertainty of [37]).

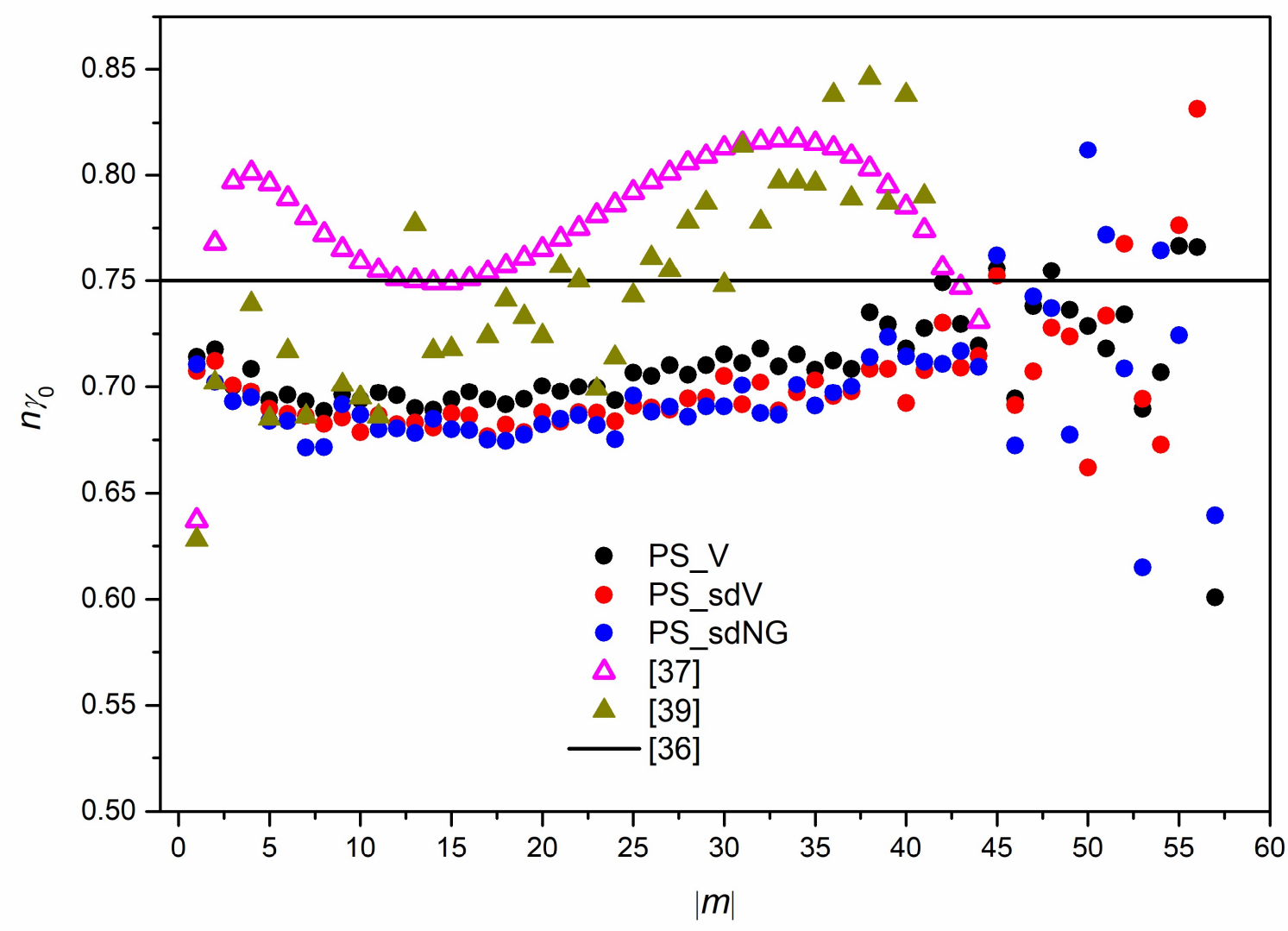


Fig. 4: The temperature dependence exponent, $n_{\gamma_{0}}$, of the collisional line broadenings, determined in this work and comparison with the experimental values of [37], [39] and the constant value (0.75) adopted in HITRAN2016 [36].

\subsection{The speed dependence of the line width}

Room temperature values of the speed dependence coefficients, $\gamma_{2}$, retrieved from the corrected-rCMDS spectra using the sdV and sdNG profiles are listed in Table 1 and plotted in Fig. 5 (the corresponding ratio $\gamma_{2} / \gamma_{0}$ being plotted in the lower panel) where they are compared with those of [14] and [15]. In [14], a value of $\gamma_{2}$ for each line was retrieved while in [15] a constant value of 0.0895 for $\gamma_{2} / \gamma_{0}$ was used for all the lines. An excellent agreement between our values and those of [14] is observed for transitions with $|m|<20$ while, for higher rotational quantum numbers, the discrepancy becomes larger. Due to lower signal to noise ratios for lines with $|m|<$ 10 and $|m|>45$ and to the numerical correlations between the various line-shape parameters (between $\gamma_{2}$ and $\beta$ for instance), larger dispersion is observed for these lines when using the sdNG profile. Note that within the quadratic approximation for the speed-dependent broadening and the power law for the temperature dependence of the line broadening coefficient, $\gamma_{2} / \gamma_{0}$ can be predicted by using Eq. (13) of [41]. The HITRAN values of the temperature exponent $n_{\gamma_{0}}$ (constant and equal to 0.75 ) were thus used to deduce the corresponding ratio. However, as shown by Fig. 5 , this prediction largely underestimates both experimental [14,15] and our rCMDS-deduced values. Better agreement is obtained when using the average value of $n_{\gamma_{0}}$ predicted by rCMDS (about 0.7). 


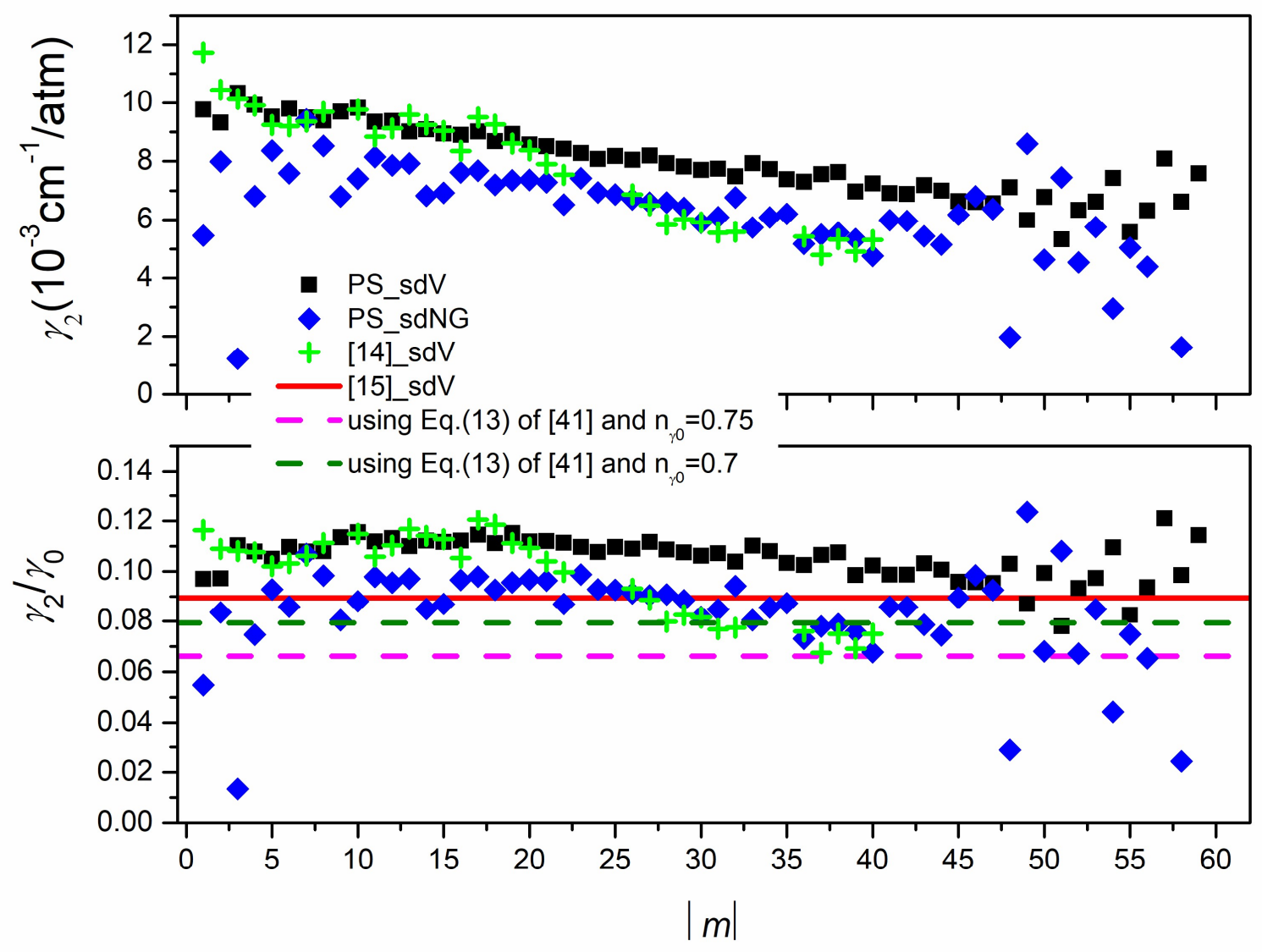

Fig. 5: Room temperature rCMDS-deduced values of the speed-dependent coefficient, $\gamma_{2}$ (top panel), and the $\gamma_{2} / \gamma_{0}$ ratio (bottom panel), for air-broadened $\mathrm{N}_{2} \mathrm{O}$, associated with the sdV (black squares) and sdNG (blue diamonds) profiles and comparison with experimental values of [14] (green crosses), [15] (red line) as well as values calculated using Eq. (13) of [41] and the temperature exponent (0.75) from HITRAN2016 [36] (dashed pink line) or the mean value (0.7) of our predicted $n_{\gamma_{0}}$ (dashed olive line).

The predicted temperature dependence exponents of the speed dependence coefficients are plotted in Fig. 6. The large dispersion of $n_{\gamma_{2}}$ is due to the relatively weak influence of $\gamma_{2}$ on the line shape and the limited signal to noise ratio of the calculated spectra. Since no rotational dependence can be observed, we recommend to use the average value of 0.51 for $n_{\gamma_{2}}$. 


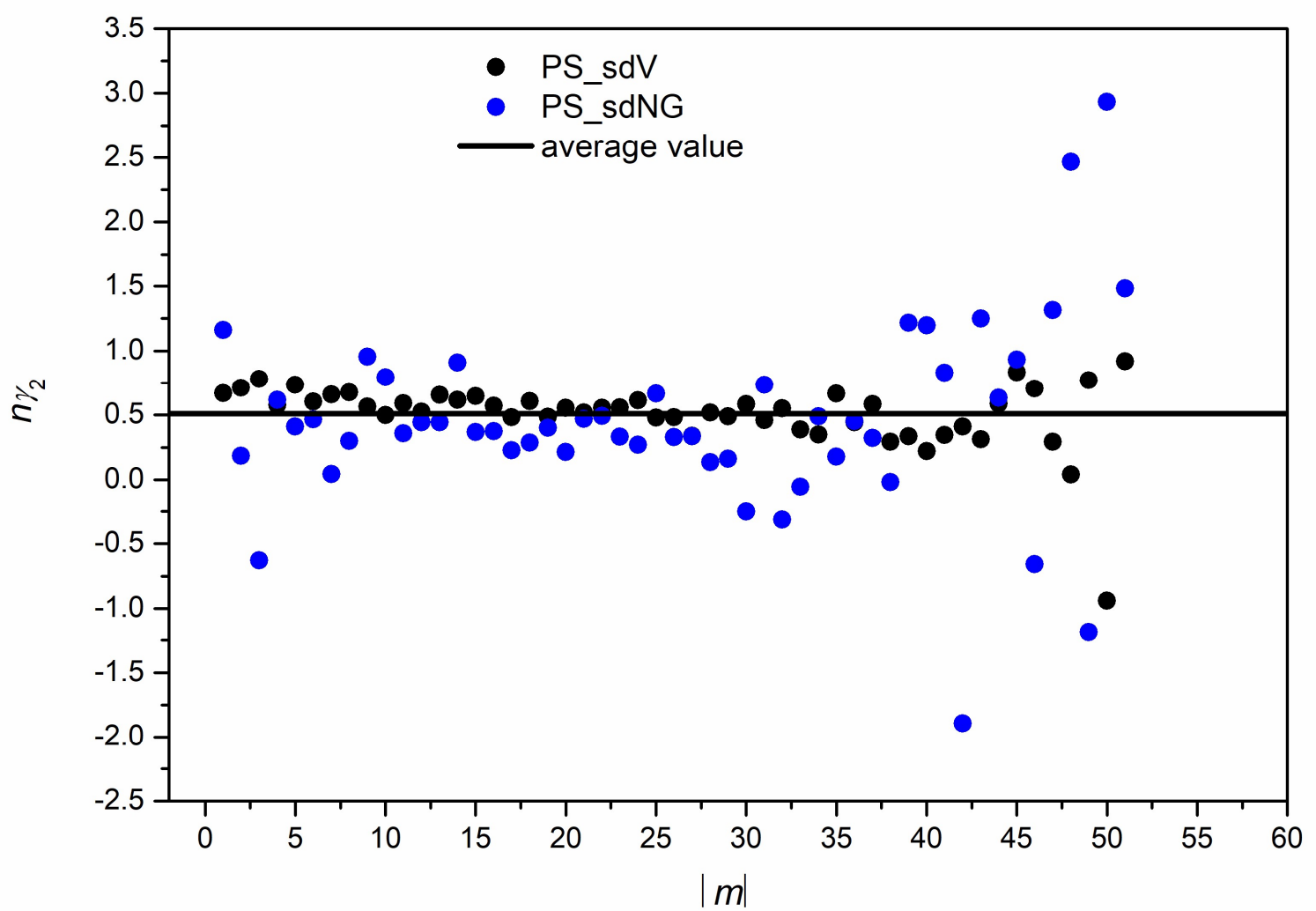

Fig. 6: Temperature exponents of the speed dependent coefficient of the line width

\subsection{The Dicke narrowing parameter}

The obtained Dicke narrowing coefficients, $\beta$, and their temperature dependences are presented in Fig. 7. To the best of our knowledge, there are no experimental nor other theoretical determination of this parameter for $\mathrm{N}_{2} \mathrm{O}$ in air using the sdNG model. Large and random rotational variations of $\beta$ and of its temperature dependence exponent are obtained, likely due to the weak influence of this parameter on the line shapes. We recommend the use of their averaged values: $\beta=3.72 \times 10^{-3} \mathrm{~cm}^{-1} / \mathrm{atm}$ and $n_{\beta}=1$. 

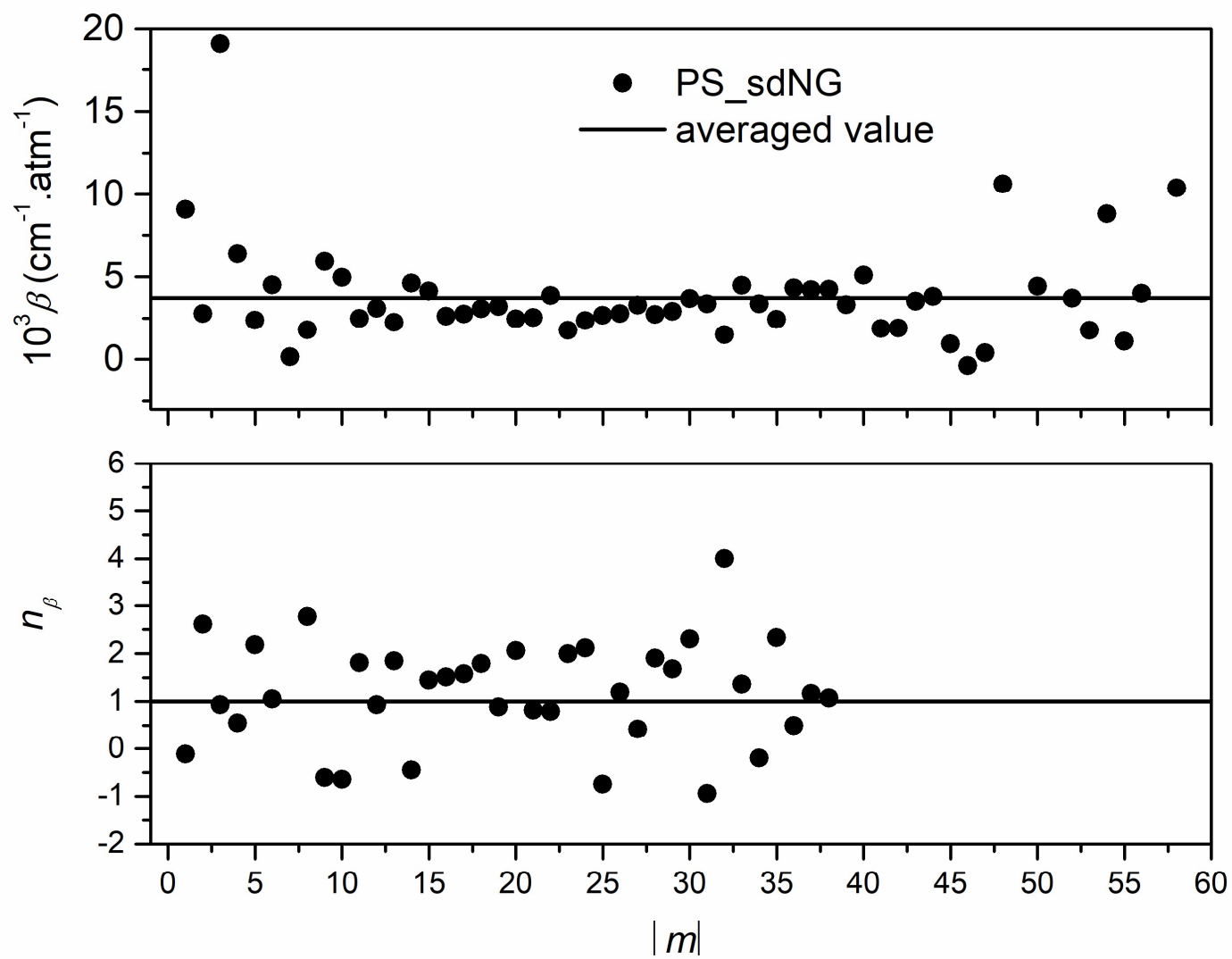

Fig. 7: The Dicke narrowing parameter, $\beta$, obtained from fits of the corrected-rCMDS calculated spectra with the sdNG profile, and its temperature dependence exponent $n_{\beta}$. The averaged values $\beta=3.72 \times 10^{-3} \mathrm{~cm}^{-1} /$ atm and $n_{\beta}=1$ are also plotted.

\subsection{The first-order line-mixing parameter}

The first-order line-mixing coefficients, $\zeta$, and their temperature dependence exponents $n_{\zeta}$ are plotted in Figs. 8 and 9, respectively. As can be observed, $\zeta$ is independent of the line profile used in the fits of the rCMDS-calculated spectra. The values of $\zeta$ obtained at room temperature are compared with the measured values of $[14,15]$ as well as with those modeled by an empirical law in [15], showing good agreements. The absolute values of $\zeta$, deduced from rCMDS are slightly larger than the experimental ones, especially at very low and high values of $|\mathrm{m}|$. To the best of our knowledge, there is no measured nor previous calculated result for the temperature dependence exponents of $\zeta$ for air-broadened $\mathrm{N}_{2} \mathrm{O}$ lines. However, the evolution of $n_{\zeta}$ with the rotational 
quantum number is very similar to that obtained from experiments and calculations for $\mathrm{CO}_{2}$ in $\mathrm{N}_{2}$ $[21,42]$ and in air [22].

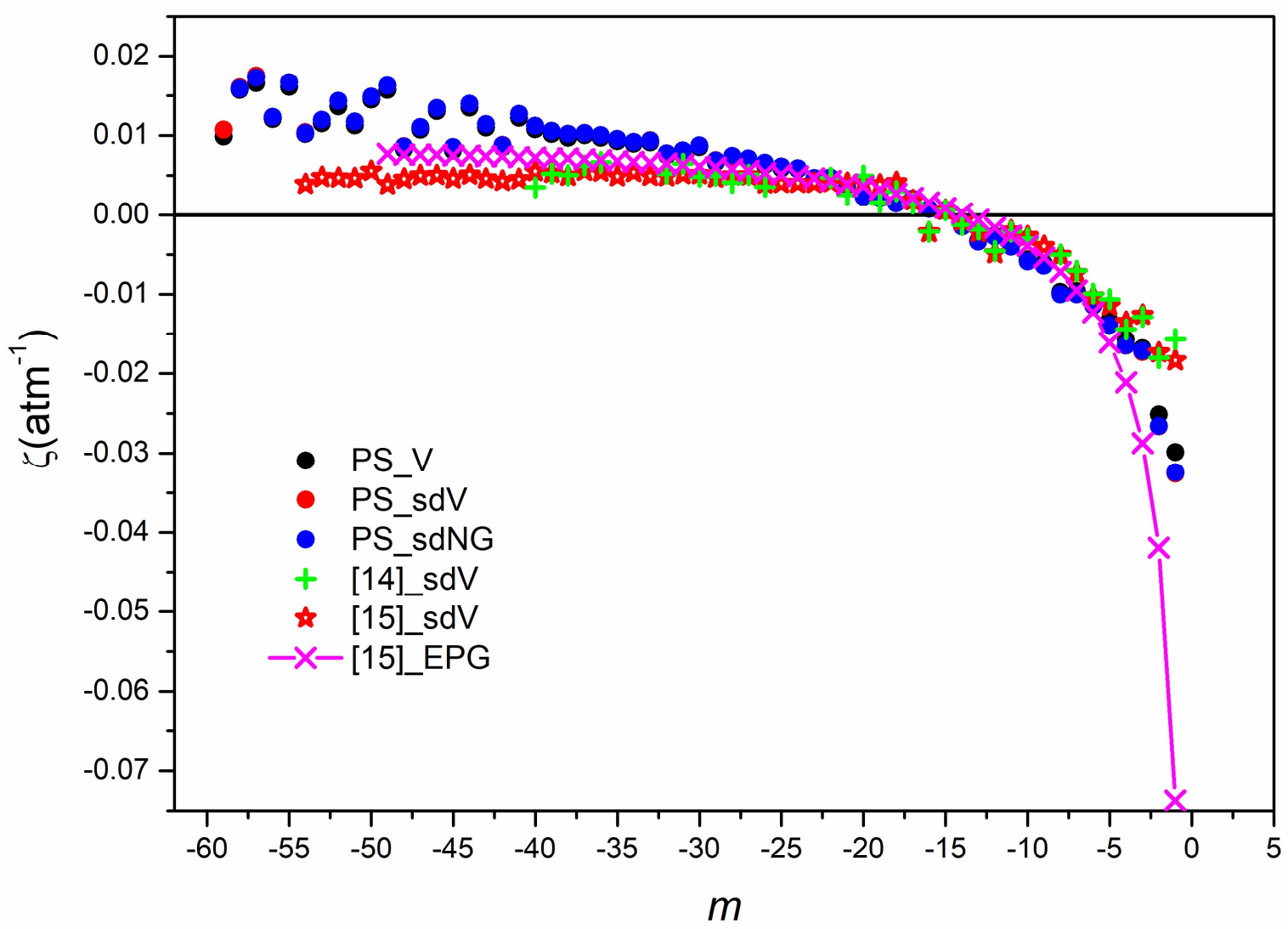

Fig. 8: First-order line-mixing coefficients deduced from spectra calculated using roomtemperature corrected-rCMDS and comparison with the measured values of [14,15] and those calculated from an EPG (Exponential Power Gap) model [15]. 


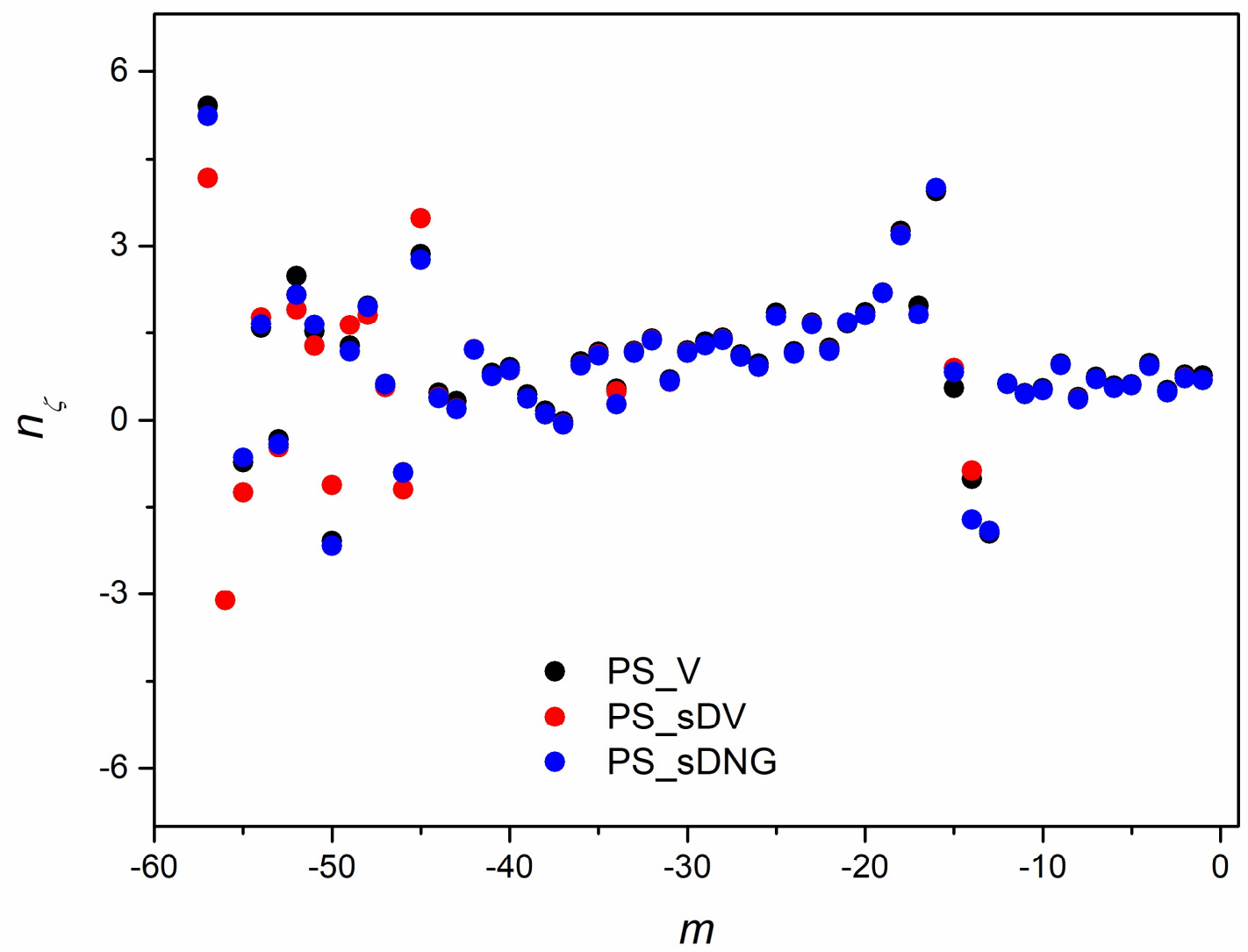

Fig. 9: The rCMDS-deduced temperature dependence exponent of the first-order line-mixing coefficient.

\section{Conclusion}

Line-shape parameter including the broadening coefficient, its speed dependent component, the Dicke narrowing and the line-mixing coefficients for air-broadened $\mathrm{N}_{2} \mathrm{O}$ lines were predicted using requantized Classical Molecular Dynamics Simulations (rCMDS) corrected using room temperature broadening coefficients measured in the $v_{3}$ band. Except for the pressureinduced line shift, the entire line-shape parameter sets, corresponding to the Voigt, the speeddependent Voigt and the speed-dependent Nelkin-Ghatak profiles including first-order line mixing are provided. The obtained line-shape parameters (except for the first order line-mixing coefficient which is branch-dependent) are valid for both the $P$ and $R$ branches. Since the vibrational dependence of the line-broadening coefficients of $\mathrm{N}_{2} \mathrm{O}$, as for $\mathrm{CO}_{2}$, is likely small, these data can be used for other vibrational bands for which no accurate and consistent experimental or theoretical 
data are available. Considering the larger dispersion of the results obtained with the sdNG profile (see Figs. 5, 6 for instance) and the fact that fit residuals obtained with this profile are not significantly better than those obtained with the $\mathrm{sdV}$, we recommend the use of the $\mathrm{sdV}$ and the associated line-shape parameters for $\mathrm{N}_{2} \mathrm{O}$ in air. Comparisons between our predicted parameters and available experimental data show good agreement. These data are certainly useful to address the precision and accuracy requirements of application as well as for populating spectroscopic databases.

\section{Acknowledgments}

The authors from Hanoi National University of Education (HNUE) are pleased to acknowledge the financial support of this research by the National Foundation for Science and Technology Development (NAFOSTED) of Vietnam under grant number of 103.03-2018.09. 


\begin{tabular}{|c|c|c|c|c|c|c|c|c|c|c|c|c|c|c|}
\hline \multirow{2}{*}{ Line } & \multicolumn{5}{|c|}{$s d V$} & \multicolumn{4}{|c|}{ V } & \multicolumn{5}{|c|}{ sdNG } \\
\hline & $\gamma_{0}$ & $n_{\gamma_{0}}$ & $\gamma_{2}$ & $\zeta$ & $n_{\zeta}$ & $\gamma_{0}$ & $n_{\gamma_{0}}$ & $\zeta$ & $n_{\zeta}$ & $\gamma_{0}$ & $n_{\gamma_{0}}$ & $\gamma_{2}$ & $\zeta$ & $n_{\zeta}$ \\
\hline $\mathrm{P}(1)$ & 100.80 & 0.82 & 9.77 & -32.56 & 0.99 & 97.11 & 0.660 & -29.89 & 0.81 & 99.73 & 1.22 & 5.46 & -32.40 & 1.16 \\
\hline $\mathrm{P}(2)$ & 95.95 & 0.71 & 9.32 & -26.62 & 0.69 & 92.40 & 0.714 & -25.14 & 0.76 & 95.57 & 0.71 & 7.99 & -26.59 & 0.69 \\
\hline $\mathrm{P}(3)$ & 93.77 & 0.71 & 10.34 & -17.31 & 0.73 & 89.68 & 0.718 & -16.83 & 0.78 & 91.94 & 0.70 & 1.23 & -17.18 & 0.72 \\
\hline $\mathrm{P}(4)$ & 92.09 & 0.70 & 9.92 & -16.52 & 0.48 & 88.20 & 0.700 & -15.79 & 0.52 & 91.21 & 0.69 & 6.81 & -16.48 & 0.48 \\
\hline $\mathrm{P}(5)$ & 90.58 & 0.70 & 9.52 & -13.90 & 0.93 & 86.86 & 0.709 & -13.34 & 0.97 & 90.23 & 0.69 & 8.37 & -13.89 & 0.93 \\
\hline $\mathrm{P}(6)$ & 89.22 & 0.69 & 9.79 & -11.45 & 0.60 & 85.34 & 0.694 & -10.98 & 0.62 & 88.56 & 0.68 & 7.60 & -11.43 & 0.60 \\
\hline $\mathrm{P}(7)$ & 88.12 & 0.69 & 9.49 & -10.01 & 0.56 & 84.37 & 0.696 & -9.61 & 0.59 & 88.10 & 0.68 & 9.42 & -10.01 & 0.55 \\
\hline $\mathrm{P}(8)$ & 87.06 & 0.69 & 9.39 & -10.03 & 0.71 & 83.35 & 0.693 & -9.73 & 0.74 & 86.79 & 0.67 & 8.53 & -10.02 & 0.70 \\
\hline $\mathrm{P}(9)$ & 85.43 & 0.68 & 9.70 & -6.41 & 0.37 & 81.54 & 0.689 & -6.14 & 0.40 & 84.58 & 0.67 & 6.80 & -6.41 & 0.36 \\
\hline $\mathrm{P}(10)$ & 84.95 & 0.69 & 9.82 & -5.87 & 0.94 & 80.99 & 0.696 & -5.62 & 0.97 & 84.21 & 0.69 & 7.41 & -5.86 & 0.94 \\
\hline $\mathrm{P}(11)$ & 83.62 & 0.68 & 9.35 & -4.02 & 0.52 & 79.88 & 0.694 & -3.86 & 0.55 & 83.24 & 0.69 & 8.15 & -4.02 & 0.52 \\
\hline $\mathrm{P}(12)$ & 82.80 & 0.69 & 9.37 & -2.75 & 0.45 & 79.03 & 0.697 & -2.62 & 0.46 & 82.33 & 0.68 & 7.86 & -2.76 & 0.45 \\
\hline $\mathrm{P}(13)$ & 82.04 & 0.68 & 9.02 & -3.40 & 0.63 & 78.44 & 0.696 & -3.28 & 0.63 & 81.70 & 0.68 & 7.93 & -3.40 & 0.62 \\
\hline $\mathrm{P}(14)$ & 81.04 & 0.68 & 9.09 & -1.46 & -1.91 & 77.40 & 0.690 & -1.38 & -1.96 & 80.37 & 0.68 & 6.83 & -1.46 & -1.91 \\
\hline $\mathrm{P}(15)$ & 80.14 & 0.68 & 8.95 & 0.56 & -0.87 & 76.55 & 0.689 & 0.60 & -1.01 & 79.53 & 0.69 & 6.92 & 0.56 & -1.71 \\
\hline $\mathrm{P}(16)$ & 79.37 & 0.69 & 8.91 & 0.74 & 0.89 & 75.79 & 0.694 & 0.78 & 0.55 & 78.97 & 0.68 & 7.63 & 0.74 & 0.82 \\
\hline $\mathrm{P}(17)$ & 78.82 & 0.69 & 9.02 & 2.05 & 4.01 & 75.17 & 0.698 & 1.94 & 3.94 & 78.39 & 0.68 & 7.68 & 2.04 & 4.0 \\
\hline $\mathrm{P}(18)$ & 78.11 & 0.68 & 8.68 & 1.48 & 1.81 & 74.62 & 0.694 & 1.46 & 1.98 & 77.65 & 0.68 & 7.19 & 1.48 & 1.82 \\
\hline $\mathrm{P}(19)$ & 77.43 & 0.68 & 8.92 & 2.13 & 3.19 & 73.81 & 0.692 & 2.11 & 3.26 & 76.94 & 0.68 & 7.36 & 2.12 & 3.19 \\
\hline $\mathrm{P}(20)$ & 76.61 & 0.68 & 8.57 & 2.36 & 2.19 & 73.16 & 0.694 & 2.31 & 2.20 & 76.24 & 0.68 & 7.37 & 2.35 & 2.20 \\
\hline $\mathrm{P}(21)$ & 76.12 & 0.69 & 8.52 & 3.61 & 1.80 & 72.68 & 0.700 & 3.55 & 1.86 & 75.74 & 0.68 & 7.29 & 3.61 & 1.80 \\
\hline $\mathrm{P}(22)$ & 75.65 & 0.68 & 8.43 & 4.70 & 1.68 & 72.26 & 0.698 & 4.58 & 1.66 & 75.09 & 0.69 & 6.52 & 4.70 & 1.68 \\
\hline $\mathrm{P}(23)$ & 75.45 & 0.69 & 8.28 & 4.63 & 1.19 & 72.12 & 0.700 & 4.49 & 1.24 & 75.18 & 0.69 & 7.43 & 4.63 & 1.19 \\
\hline $\mathrm{P}(24)$ & 75.05 & 0.69 & 8.07 & 5.88 & 1.65 & 71.83 & 0.700 & 5.77 & 1.68 & 74.71 & 0.68 & 6.93 & 5.87 & 1.64 \\
\hline$P(25)$ & 74.60 & 0.68 & 8.18 & 6.08 & 1.14 & 71.32 & 0.694 & 5.86 & 1.18 & 74.21 & 0.68 & 6.87 & 6.08 & 1.14 \\
\hline $\mathrm{P}(26)$ & 73.81 & 0.69 & 8.05 & 6.56 & 1.79 & 70.58 & 0.707 & 6.32 & 1.86 & 73.41 & 0.70 & 6.69 & 6.56 & 1.79 \\
\hline $\mathrm{P}(27)$ & 73.45 & 0.69 & 8.20 & 7.07 & 0.92 & 70.13 & 0.705 & 6.84 & 0.97 & 72.97 & 0.69 & 6.59 & 7.07 & 0.92 \\
\hline
\end{tabular}




\begin{tabular}{|c|c|c|c|c|c|c|c|c|c|c|c|c|c|c|}
\hline $\mathrm{P}(28)$ & 73.05 & 0.69 & 7.93 & 7.43 & 1.09 & 69.87 & 0.71 & 7.22 & 1.12 & 72.65 & 0.69 & 6.59 & 7.43 & 1.09 \\
\hline $\mathrm{P}(29)$ & 72.83 & 0.69 & 7.83 & 6.86 & 1.38 & 69.69 & 0.71 & 6.64 & 1.41 & 72.41 & 0.69 & 6.41 & 6.85 & 1.37 \\
\hline $\mathrm{P}(30)$ & 72.51 & 0.70 & 7.70 & 8.73 & 1.28 & 69.44 & 0.71 & 8.52 & 1.34 & 72.01 & 0.69 & 5.90 & 8.73 & 1.29 \\
\hline $\mathrm{P}(31)$ & 72.30 & 0.71 & 7.75 & 8.11 & 1.16 & 69.20 & 0.72 & 7.90 & 1.19 & 71.83 & 0.69 & 6.09 & 8.12 & 1.16 \\
\hline $\mathrm{P}(32)$ & 72.10 & 0.69 & 7.49 & 7.73 & 0.66 & 69.12 & 0.71 & 7.51 & 0.70 & 71.89 & 0.70 & 6.76 & 7.72 & 0.66 \\
\hline $\mathrm{P}(33)$ & 71.96 & 0.70 & 7.93 & 9.36 & 1.37 & 68.76 & 0.72 & 9.12 & 0.14 & 71.34 & 0.69 & 5.74 & 9.34 & 1.36 \\
\hline $\mathrm{P}(34)$ & 71.67 & 0.69 & 7.74 & 9.17 & 1.16 & 68.56 & 0.71 & 8.95 & 1.18 & 71.20 & 0.69 & 6.08 & 9.15 & 1.16 \\
\hline $\mathrm{P}(35)$ & 71.42 & 0.70 & 7.38 & 9.55 & 0.50 & 68.49 & 0.72 & 9.25 & 0.54 & 71.08 & 0.70 & 6.20 & 9.55 & 0.28 \\
\hline $\mathrm{P}(36)$ & 71.30 & 0.70 & 7.30 & 10.01 & 1.12 & 68.41 & 0.71 & 9.69 & 1.17 & 70.73 & 0.69 & 5.17 & 10.01 & 1.11 \\
\hline $\mathrm{P}(37)$ & 71.00 & 0.70 & 7.57 & 10.27 & 0.94 & 67.97 & 0.71 & 10.00 & 1.01 & 70.43 & 0.70 & 5.49 & 10.26 & 0.94 \\
\hline $\mathrm{P}(38)$ & 71.00 & 0.70 & 7.63 & 10.17 & -0.06 & 67.94 & 0.71 & 9.69 & -0.02 & 70.43 & 0.70 & 5.55 & 10.17 & -0.07 \\
\hline $\mathrm{P}(39)$ & 70.76 & 0.71 & 6.97 & 10.54 & 0.11 & 68.02 & 0.74 & 10.16 & 0.16 & 70.33 & 0.71 & 5.34 & 10.53 & 0.10 \\
\hline $\mathrm{P}(40)$ & 70.77 & 0.71 & 7.24 & 11.21 & 0.37 & 67.90 & 0.73 & 10.78 & 0.44 & 70.14 & 0.72 & 4.75 & 11.18 & 0.37 \\
\hline $\mathrm{P}(41)$ & 70.05 & 0.69 & 6.91 & 12.69 & 0.85 & 67.34 & 0.72 & 12.21 & 0.91 & 69.80 & 0.71 & 5.99 & 12.69 & 0.86 \\
\hline $\mathrm{P}(42)$ & 69.86 & 0.71 & 6.88 & 8.77 & 0.76 & 67.15 & 0.73 & 8.49 & 0.81 & 69.61 & 0.71 & 5.96 & 8.77 & 0.76 \\
\hline $\mathrm{P}(43)$ & 69.66 & 0.73 & 7.19 & 11.42 & 1.21 & 66.80 & 0.75 & 10.99 & 1.21 & 69.18 & 0.71 & 5.44 & 11.40 & 1.21 \\
\hline $\mathrm{P}(44)$ & 69.49 & 0.71 & 6.70 & 13.98 & 0.20 & 66.72 & 0.73 & 13.48 & 0.33 & 69.00 & 0.72 & 5.14 & 13.96 & 0.20 \\
\hline $\mathrm{P}(45)$ & 69.23 & 0.72 & 6.63 & 8.53 & 0.40 & 66.65 & 0.72 & 8.10 & 0.47 & 69.11 & 0.71 & 6.18 & 8.53 & 0.38 \\
\hline $\mathrm{P}(46)$ & 69.14 & 0.75 & 6.61 & 13.44 & 3.47 & 66.56 & 0.76 & 13.03 & 2.86 & 69.20 & 0.76 & 6.80 & 13.44 & 2.76 \\
\hline $\mathrm{P}(47)$ & 68.89 & 0.69 & 6.57 & 11.05 & -1.20 & 66.31 & 0.69 & 10.69 & -0.90 & 68.83 & 0.67 & 6.37 & 11.05 & -0.91 \\
\hline $\mathrm{P}(48)$ & 69.10 & 0.71 & 7.11 & 8.62 & 0.57 & 66.28 & 0.74 & 8.26 & 0.62 & 68.05 & 0.74 & 1.97 & 8.60 & 0.62 \\
\hline $\mathrm{P}(49)$ & 68.77 & 0.73 & 5.98 & 16.22 & 1.81 & 66.48 & 0.76 & 15.72 & 1.97 & 69.61 & 0.74 & 8.60 & 16.26 & 1.95 \\
\hline $\mathrm{P}(50)$ & 68.29 & 0.72 & 6.78 & 14.88 & 1.63 & 65.61 & 0.74 & 14.46 & 1.28 & 67.74 & 0.68 & 4.62 & 14.84 & 1.17 \\
\hline $\mathrm{P}(51)$ & 68.32 & 0.66 & 5.33 & 11.74 & -1.12 & 66.33 & 0.73 & 11.26 & -2.09 & 68.92 & 0.81 & 7.44 & 11.71 & -2.17 \\
\hline $\mathrm{P}(52)$ & 67.94 & 0.73 & 6.33 & 14.33 & 1.27 & 65.48 & 0.72 & 13.62 & 1.52 & 67.51 & 0.77 & 4.54 & 14.33 & 1.65 \\
\hline $\mathrm{P}(53)$ & 68.08 & 0.77 & 6.62 & 11.94 & 1.91 & 65.46 & 0.73 & 11.50 & 2.49 & 67.84 & 0.71 & 5.75 & 11.93 & 2.16 \\
\hline $\mathrm{P}(54)$ & 67.86 & 0.69 & 7.43 & 10.40 & -0.46 & 64.86 & 0.69 & 10.20 & -0.33 & 66.79 & 0.62 & 2.96 & 10.28 & -0.41 \\
\hline $\mathrm{P}(55)$ & 67.51 & 0.67 & 5.58 & 16.64 & 1.77 & 65.40 & 0.71 & 16.06 & 1.59 & 67.38 & 0.77 & 5.04 & 16.64 & 1.65 \\
\hline $\mathrm{P}(56)$ & 67.59 & 0.78 & 6.32 & 12.32 & -1.25 & 65.12 & 0.77 & 12.05 & -0.73 & 67.12 & 0.72 & 4.38 & 12.32 & -0.64 \\
\hline
\end{tabular}




\begin{tabular}{|c|c|c|c|c|c|c|c|c|c|c|c|c|c|c|}
\hline $\mathrm{P}(57)$ & 66.84 & 0.83 & 8.09 & 17.52 & -3.11 & 63.50 & 0.77 & 16.56 & & 65.61 & 0.90 & -5.44 & 17.25 & -8.50 \\
\hline $\mathrm{P}(58)$ & 67.30 & 0.40 & 6.63 & 16.02 & 4.18 & 64.69 & 0.60 & 15.68 & 5.42 & 66.33 & 0.64 & 1.62 & 15.85 & 5.24 \\
\hline $\mathrm{P}(59)$ & 66.42 & & 7.59 & 10.72 & & 63.31 & & 9.85 & & & & & & \\
\hline
\end{tabular}

Table 1: Air-broadened line-shape parameters for $\mathrm{N}_{2} \mathrm{O}$ lines, deduced from fits of rCMDS-calculated spectra with the $\mathrm{V}$, the sdV and the sdNG profile, all of them including the first-order line mixing. $\gamma_{0}, \gamma_{2}$ and $\zeta$ are respectively the broadening coefficient, the speed dependence coefficient of the line broadening (both in $10^{-3} \mathrm{~cm}^{-1} / \mathrm{atm}$ ) and the first-order line-mixing coefficient (in $10^{-3} \mathrm{~atm}^{-1}$ ) at room temperature (296K). $n_{\gamma_{0}}$ and $n_{\zeta}$ are the temperature dependence exponents of the line broadening and mixing coefficients, respectively. The Dicke narrowing coefficient, $\beta$, and its temperature dependence exponent, $n_{\beta}$, (for the sdNG profile) as well as the temperature dependence exponent of $\gamma_{2}, n_{\gamma_{2}}$, are independent of the rotational quantum number; $\beta=3.7210^{-3} \mathrm{~cm}^{-1} / \mathrm{atm}, n_{\beta}=1$ and $n_{\gamma_{2}}=0.51$ (see text). 


\section{References}

[1] Crutzen P J. The influence of nitrogen oxides on the atmospheric ozone content. Quart J R Met Soc 1970;96:320-5. https://doi.org/10.1002/qj.49709640815

[2] Machida T, Nakazawa T, Fujii Y, Aoki S, Watanabe O. Increase in the atmospheric nitrous oxide concentration during the last 250 years. Geophys Res Lett 1995;22:2921-24. https://doi.org/10.1029/95GL02822

[3] Ravishankara AR, Daniel JS, Portmann RW. Nitrous oxide $\left(\mathrm{N}_{2} \mathrm{O}\right)$ : the dominant ozonedepleting substance emitted in the 21st century. Science, 2009;326:123-5. 10.1126/science. 1176985

[4] Rapson TD, Dacres H. Analytical techniques for measuring nitrous oxide. Trends Anal Chem 2014;54:65-74.

[5] Xiong X, Maddy ES, Barnet C, Gambacorta A, Patra PK, Sun F, Goldberg M. J Geophys Res 2014;119:9107-22. doi:10.1002/2013JD021406.

[6] Plieninger J, von Clarmann T, Stiller GP, Grabowski U, Glatthot N, Kellmann S, Linden A, Haenel F, Kiefer M, Hopfner M, Laeng A, Lossow S. Methane and nitrous oxide retrievals from MIPAS-ENVISAT. Atmos Meas Tech 2015;8:4657-70. Doi:10.5194/amt-8-4657-2015

[7] Zhou M, Langerock B, Wells KC, Millet DB, Vigouroux C, Sha MK et al. An intercomparison of total column-averaged nitrous oxide between ground-based FTIR TCCON and NDACC measurements at seven sites and comparisons with the GEOS-Chem model. Atmos Meas Tech 2019;12:1393-1408. https://doi.org/10.5194/amt-12-1393-2019

[8] Mendonca J, Strong K, Wunnch D, Toon GC, Long DA, Hodges JT, Sironneau VT, Franklin JE. Atmos Meas tech 2019;12:35-50.

[9] Hartmann JM, Tran H, Toon GC. Influence of line mixing on the retrieval of atmospheric $\mathrm{CO}_{2}$ from spectra in the 1.6 and $2.1 \mu \mathrm{m}$ regions. Atmos Chem Phys 2009;9:7303-12.

[10] Strow LL, Pine AS. $Q$-branch line mixing in $\mathrm{N}_{2} \mathrm{O}$ : effects of $l$-type doubling. J Chem Phys 1988;89:1427-34, 10.1063/1.455142

[11] Margottin-Maclou M, Henry A, Valentin A. Line mixing in the $Q$ branches of the $v_{1}+v_{2}$ band of nitrous oxide and of the $\left(11^{1} 0\right)_{I} \leftarrow\left(02^{2} 0\right)$ band of carbon dioxide. J Chem Phys 1992;96:1715$23,10.1063 / 1.462126$

[12] Hartmann JM, Bouanich JP, Jucks KW, Blanquet G, Walrand J, Bermejo D, et al. Line-mixing effects in $\mathrm{N}_{2} \mathrm{O} Q$ branches: model, laboratory, and atmospheric spectra. J Chem Phys 1999;110:1959-68, 10.1063/1.477862

[13] Vitcu A, Ciurylo R, Wehr R, Drummond JR, May AD. Broadening, shifting, and line mixing in the $03^{1} 0 \leftarrow 01^{1} 0$ parallel $Q$ branch of $\mathrm{N}_{2} \mathrm{O}$. J Mol Spectrosc 2004;226:71-80, 10.1016/j.jms.2004.03.017

[14] Loos J, Birk M, Wagner G. Pressure broadening, -shift, speed dependence and line mixing in the $v_{3}$ rovibational band of $\mathrm{N}_{2} \mathrm{O}$. J Quant Spectrosc Transf 2015;151:300-9.

[15] Predoi-Cross A, Hashemi R, Naseri H. Analysis of Fourier transform spectra of $\mathrm{N}_{2} \mathrm{O}$ in the $v_{3}$ band for atmospheric composition retrievals. Can J Phys 2018;96:454-64.

[16] Liu GL, Wang J, Tan Y, Kang P, Bi Z, Liu AW, Hu SM. Line positions and $\mathrm{N}_{2}$-induced line parameters of the $00^{0} 3-00^{0} 0$ band of ${ }^{14} \mathrm{~N}_{2}{ }^{16} \mathrm{O}$ by comb-assisted cavity ring-down spectroscopy. J Quant Spectrosc Transf 2019;229:17-22.

[17] Odintsova TA, Fasci E, Gravina S, Gianfrani L, Castrillo A. Optical feedback laser absorption spectroscopy of $\mathrm{N}_{2} \mathrm{O}$ at $2 \mu \mathrm{m}$. J Quant Spectrosc Transf 2020;254:107190. 
[18] Stankiewicz K, Jozwiak H, Gancewski M, Stolarczyk N, Thibault F, Wcislo P. Ab initio calculations of collisional line-shape parameters and generalized spectroscopic cross-sections for rovibrational dipole lines in HD perturbed by He. J Quant Spectrosc Rad Transf 2020;254:107194.

[19]Slowinski M, Thibault F, Tan Y, Wang J, Liu AW, Hu SM, Kassi S, Campargue A, Konefal M, Jozwiak H, Patkowski K, Zuchowski P, Ciurylo R, Lisak D, Wcislo P. $\mathrm{H}_{2}-\mathrm{He}$ collisions: ab initio theory meets cavity-enhanced spectra. Phys Rev A 2020;101:052705.

[20] Kowzan G, Cybulski H, Wcislo P, Slowinski M, Viel A, Maslowski P, Thibault F. Subpercent agreement between $\mathrm{ab}$ initio and experimental collision-induced line shaoes of carbone monoxide perturbed by argon.

[21] Nguyen HT, Ngo NH, Tran H. Prediction of line shape parameters and their temperature dependences for $\mathrm{CO}_{2}-\mathrm{N}_{2}$ using molecular dynamics simulations. $\mathrm{J}$ Chem Phys 2018;149:224301

[22] Nguyen HT, Ngo NH, Tran H. Line-shape parameters and their temperature dependences predicted from molecular dynamics simulations for $\mathrm{O}_{2}$ - and air-broadened $\mathrm{CO}_{2}$ lines. J Quant Spectrosc Rad Transf 2020;242:106729 https://doi.org/10.1016/j.jqsrt.2019.106729.

[23] Ngo NH, Hartmann JM. A strategy to complete databases with parameters of refined line shapes and its test for CO in He, Ar and Kr. J Quant Spectrosc Rad Transf 2017;203:334-40, http://dx.doi.org/10.1016/j.jqsrt.2017.01.031.

[24] Tran DD, Sironneau VT, Hodges JT, Armante R, Cuesta J, Tran H. Prediction of high-order line-shape parameters for air-broadenened $\mathrm{O}_{2}$ lines using requantized classical molecular dynamics simulations and comparison with measurements. J Quant Spectrosc Rad Transf 2019;222-223:108-14.

[25] Allen MP and Tildesley DJ. Computer Simulations of Liquids, Oxford University Press, Oxford 1987.

[26] Hartmann JM, Tran H, Ngo NH, Landsheere X, Chelin P, Lu Y, Liu AW, Hu SM, Gianfrani L, Casa G, Castrillo A, Lepère M, Delière Q, Dhyne M, Fissiaux L. Ab initio calculations of the spectral shapes of $\mathrm{CO}_{2}$ isolated lines including non-Voigt effects and comparisons with experiments. Phys Rev A 2013;87:013403.

[27] Rohart F, Colmont JM, Wlodarczak G, Bouanich JP. $\mathrm{N}_{2}$ - and $\mathrm{O}_{2}$-broadening coefficients and profiles for millimeter lines of ${ }^{14} \mathrm{~N}_{2} \mathrm{O}$. J Mol Spectrosc 2003;222:159-171.

[28] Bouanich P. Site-site Lennard-Jones potential parameters for $\mathrm{N}_{2}, \mathrm{O}_{2}, \mathrm{H}_{2}, \mathrm{CO}$ and $\mathrm{CO}_{2}$. J Quant Spectrosc Radiat Transfer 1992;47:243-50.

[29] Hirschfelder JE, Curtiss CF, Bird RB. Molecular theory of gases and liquids, Wiley, New York (1954)

[30] Speed-dependent collisional width and shift parameters in spectral profiles. J Quant Spectrosc Radiat Transf 1972;9:1331-42.

[31] Lance B, Blanquet G, Walrand J, Bouanich JP. On the speed-dependent hard collision lineshape models: application to $\mathrm{C}_{2} \mathrm{H}_{2}$ perturbed by Xe. J Mol Spectrosc 1997;185:262-71.

[32] Ngo NH, Lisak D, Tran H, Hartmann JM. An isolated line-shape model to go beyond the Voigt profile in spectroscopic databases and radiative transfer codes. J Quant Spectrosco Radiat Transf 2013;129:89-100.

[33] Rohart F, Mader H, Nicolaisen HW. Speed dependence of rotational relaxation induced by foreign gas collisions: studies on $\mathrm{CH}_{3} \mathrm{~F}$ by millimeter wave coherent transients. J Chem Phys 1994;101:6475-86. 
[34] Rohart F, Ellendt A, Kaghat F, Mäder H. Self and polar foreign gas line broadening and frequency shifting of $\mathrm{CH}_{3} \mathrm{~F}$ : effect on the speed dependence observed by millimeter-wave coherent transients. J Mol Spectrosc 1997;185:222-33.

[35] Rosankrankz P. Shape of the $5 \mathrm{~mm}$ oxygen band in the atmosphere. IEEE Trans Antennas Propag 1975;23:498-506.

[36] Gordon IE, Rothman LS, Hill C et al. The HITRAN2016 molecular spectroscopic database. J Quant. Spectrosc. Radi Transf 2017;203:3-69, https://doi.org/10.1016/j.jqsrt.2017.06.038.

[37] Lacome N, Levy A, Guelachvili G. Fourier transform measurement of self-, $\mathrm{N}_{2}-$ and $\mathrm{O}_{2}-$ broadening of $\mathrm{N}_{2} \mathrm{O}$ lines: temperature dependence of linewidths. Appl Opt 1984;23:425-35.

[38] Toth RA. $\mathrm{N}_{2}$ - and air-broadened line widths and frequency-shifts of $\mathrm{N}_{2} \mathrm{O}$. J Quant Spectrosc Rad Transf 2000;66:285-304.

[39] Nemtchinov V, Sun C, Varanasi P. Measurements of line intensities and line widths in the $v_{3}-$ fundamental band of nitrous oxide at atmospheric temperatures. J Quant Spectrosc Rad Transf 2004;83:267-84, doi:10.1016/S0022-4073(02)00355-2.

[40] Nakayama T, Fukuda H, Sugita A et al. Buffer-gas pressure broadening for the (003)-(000) band of $\mathrm{N}_{2} \mathrm{O}$ measured with continuous-wave cavity ring-down spectroscopy. Chem Phys 2007;334:196-203. doi:10.1016/j.chemphys.2007.03.001.

[41] Ghysels M, Liu Q, Fleisher AJ, Hodges JT. A variable temperature cavity ring down spectrometer with application to line shape analysis of $\mathrm{CO}_{2}$ spectra in the $1600 \mathrm{~nm}$ region. Appl Phys B 2017;123-124. doi:10.1007/s00340-017-6686-y

[42] Wilzewski JS, Birk M, Loos J, Wagner G. Temperature-dependence laws of absorption line shape parameters of the $\mathrm{CO}_{2} v_{3}$ band. J Quant Spectrosc Rad Transf 2018;206:296-305. 296305 